\title{
NUMERICAL ANALYSIS OF NATURAL CONVECTION IN A HEATED ROOM AND ITS IMPLICATION ON THERMAL COMFORT
}

\author{
A. Sibo Anthony ${ }^{1}$, Tikendra Nath Verma ${ }^{2}$
}

\begin{abstract}
A heated room is numerically analyzed to study thermal comfort. Cold air flowing in from the inlet gets heated by a heat source (placed just below the inlet), before being distributed throughout the room. The presence of the heat source and a high Rayleigh number causes the flow of air to be buoyant and turbulent. Two RANS based turbulence models, RNG $k-\varepsilon$ and $k-\omega$ SST turbulence models are used to model turbulence and the Discrete Ordinate (DO) radiation model is used to model radiation heat transfer between different surfaces in the room. In order to account for buoyant air movement, air is approximated as a Boussinesq fluid. Parameters that affect comfort such as comfort temperature, operative temperature, turbulence intensity, velocity and the temperature difference between the head and ankle level are investigated. It is found that the comfort temperature and operative temperature predicted in this study have similar profiles irrespective of the turbulence models. Predicted values of turbulence intensity and velocity were low, which shows a low risk of drought in the occupied zone. The two RANS models give results similar to earlier studies that were performed with different turbulence and radiation models, proving their robustness and viability for a variety of flow problems.
\end{abstract}

\section{Keywords: Natural Convection, Turbulence Intensities, Air Velocity, Comfort Temperature, Operative Temperature}

\section{INTRODUCTION}

Most times, rooms are heated during cold seasons to improve comfort conditions. The nature of flow in a room is affected by the presence of a heat source as it induces a temperature gradient resulting in a buoyant air movement. This influences the motion of air in the room. The heat source also exchanges thermal radiation with the surfaces of the walls and occupants of the room, so comfort depends on the combined effects of radiation and natural convection heat transfer. Though air velocity is small, flow, in this case, have a high Rayleigh number (Table 1) and therefore have a turbulent character. A high level of turbulence coupled with air movement will increase the rate at which heat is convected away from warm bodies causing unwanted cooling.

Intuitively humans seek comfort in their environment. A comfortable environment enhances the quality of living, improves health and increases productivity. Thermal comfort is defined as a state of mind where a person is satisfied with the environment [1-3]. The factors that influence thermal comfort are divided into environmental and cultural. The environmental factors are mean air temperature, mean radiant temperature, air velocity, turbulence intensity and humidity; and the cultural factors are clothing and activity level of individuals.

Natural convection is a pervasive phenomenon and have a considerable amount of research published in the literature. Recent researches (experimental and numerical) have made extensive investigations on natural convection mixed with other modes of heat transfer such as forced convection and boiling. Most of these researches have also used nanoparticles as a heat transfer medium. Some of these recent researches are discussed in this section. Sarafraz et al. [4] conducted experiments to quantify the forced convection and nucleate boiling heat transfer coefficients of $\mathrm{Al}_{2} \mathrm{O}_{3}$ water based nanofluid. In another experiment, pool boiling heat transfer coefficient was experimentally quantified for a functionalised and non-functionalised carbon nanotube fluids [5]. Nakhjavani et al. [6], analyzed the thermal behaviour of silver nano-particles produced via a green synthesis method. Aghaei et al. [7], did a numerical study of mixed convection of a nano fluid inside enclosure. An experimental investigation was performed by Sarafraz et al. [8] to study the thermal performance of $\mathrm{CuO} / \mathrm{water}$ nanofluid in a heat exchanger. Safaei et al. [9], performed a numerical study of laminar mixed convection heat transfer in a square enclosure. They compared the heat transfer performance of a Newtonian and a non-Newtonian fluid. Another numerical study on turbulent and laminar mixed convection in a room was conducted by Safaei et

This paper was recommended for publication in revised form by Regional Editor Mohammad Safaei

${ }^{1}$ Department of Mechanical Engineering, Maulana Azad National Institute of Technology, Bhopal, India

2 Maulana Azad National Institute of Technology, Bhopal, Madhya Pradesh, India

${ }^{*}$ E-mail address: verma.tikks@gmail.com 
al. [10]. They observed that a low Richardson number increased the heat transfer rate. A laterally heated square enclosure filled with air was numerically studied by implementing different methods [11]. The Finite Volume Method (FVM) was used in a numerical study to the study the effect of radiation on laminar and turbulent mixed convection heat transfer in a semi-transparent medium [12]. Nikkhah et al. [13], experimentally quantified the convective boiling heat transfer co-efficient of spherical $\mathrm{CuO}$ (II) nanoparticles dispersed in water under forced convection and nucleate boiling. Goodarzi et al. [14], developed a nanoscale method of lattice boltzmann to predict fluid flow and heat transfer in an inclined lid driven 2D cavity with a heat source. A two phase mixture was used to study laminar and turbulent mixed convection heat transfer of water/Cu nano fluids [15]. Numerical simulations have also been used in varied fields of studies such as wind pressure distribution on buildings [16], dual-fuel diesel engine [17], nanofluidic thermosyphon heat exchanger [18], water quality rehabilitation with rainwater [19], modelling of hydrogen production [20] and pollutant transport in rivers [21].

Numerical methods such as CFD have been used to study ventilation flows for a wide variety of application such as parking lots [22], passive cooling [23], radiant heated ceiling[24], effect of insulating wall paints on space conditioning [25], underground car parks[26], office rooms[27], natural ventilation [28] and pollution in hospital [29-35] . In general it is more cheaper and faster than the analytical and experimental methods. Thermal comfort can be numerically analyzed with the help of Computational Fluid Dynamics (CFD), which has become an important tool in the study of fluid mechanics and heat transfer. The various parameters that affect thermal comfort can be simulated in two dimensional or three-dimensional enclosures, where boundary conditions along with turbulence and heat transfer models are appropriately implemented in order to present a realistic model of the complex phenomena that occurs within the flow domain. The complexity in the simulation of air flow and heat transfer in an enclosure is because of the buoyant air movement, resulting from the temperature gradient induced by the heat source.

Teodosiu et al. [36], examined the capacity and accuracy of CFD model to characterize thermo-aeraulic behaviour of a heated room. They concluded that the CFD method can be employed in detail studies of thermal comfort, indoor air quality and energy consumption. Myhren and Holmberg [37] studied the effect of different space heating systems and their positions on indoor climate using a low Reynolds number turbulence model adjusted for indoor air simulation. In another study, different positions for ventilation air inlet were used to study radiation heat output and comfort temperature [38]. Horikiri et al., [39] studied the conjugate heat transfer in a domestic model room with finite wall thickness and a heat source. They also studied the level of comfort temperature and the temperature distribution in both the solid wall and the indoor air. A CFD analysis was conducted to understand the correlations between heat generation, ventilation velocity and thermal sensation index [40]. The operative temperature and comfort temperature were compared in a CFD simulation of a room model [41].

The factors affecting thermal comfort are many and a detailed investigation of all of them is beyond the scope of most research. However, the knowledge of the effect of temperature and velocity is well known as many studies have shown and other factors such as turbulence intensity also have important implications for comfort as studies show that at a high level it increases the risk of drought. These factors act together to impact the sensation of comfort or dissatisfaction of occupants in a room and therefore, their combined effects should be studied for an accurate representation of the indoor environment. This work investigates turbulence intensity, velocity, operative temperature, comfort temperature and the temperature difference between the head and ankle level in a room heated by a radiator. The implication of these factors on thermal comfort is studied. The factors are reproduced numerically by using the RNG $k-\varepsilon$ and the $k-\omega$ turbulence models. A comparison of the two turbulence models is also presented.

\section{METHODOLOGY}

This section presents the methodologies adopted in running the numerical simulation and in processing the resulting data. Post-Processing is necessary to make the large volume of data generated from the simulations meaningful. The open source programming language Python, along with its libraries for plotting, data analysis, numerical analysis and statistical data visualisation are used for extracting meaningful information from the data. An open source post processing tool, Paraview, is also used for plotting vector and velocity contours. Numerical simulations were carried out using a commercial CFD code, Ansys Fluent, which uses the finite volume method for the discretization of the governing equations. The SIMPLE algorithm, introduced by Patankar and Spalding 
[42] is used for the velocity - pressure coupling. In flows with a strong buoyancy, the Body Forced Weighted scheme works well for the interpolation of pressure at the faces and hence, is adopted in this numerical study. The gradients of diffusion and convection terms are computed with the Least Squares Cell-Based method. A Second Order Upwind scheme was used for the interpolation of scalars on the cell faces [43].

In order to check the consistency of the numerical results, simulations were performed on three different grids, with the number of cells ranging from 300000 to 500000. A final grid size of 492702 elements was chosen for further analysis.

A model of a room with dimensions of $4.8 \times 2.4 \times 2.7 \mathrm{~m}^{3}$ was constructed for the simulation works. The room has an inlet, an exhaust, a window and a heating element (radiator) which serves as a source of heat. The heating element or the heat source has a dimension of $2 \times 0.55 \times 0.116 \mathrm{~m}^{3}$ and the inlet is situated above the window and has a dimension of $0.4 \times 0.03 \mathrm{~m}^{2}$. The Window has a dimension of $1.2 \times 2.4 \mathrm{~m}^{2}$ and is placed on the left wall just above the heat source. Due to the presence of the heat source, radiative heat transfer has a strong effect on the thermal environment and therefore it is modelled in the simulations. An air change rate of $0.8 \mathrm{~h}^{-1}$ results in a volume flow rate of about $7 \mathrm{Ls}^{-1}$ at the inlet. A constant temperature boundary condition is assumed for the heat source and the window with a temperature of $42^{\circ} \mathrm{C}$ and $14^{\circ} \mathrm{C}$ respectively. Air inlet temperature is kept at $-5^{\circ} \mathrm{C}$. On the other hand, the walls have been approximated as adiabatic. The turbulence in the room was simulated using RNG $k-\varepsilon$ and $k-\omega$ SST turbulence models, which are based on the Reynolds Average Navier Stokes (RANS) equations. Air has been approximated as a Boussinesq fluid. Discrete Ordinates (DO) radiation model is used for the simulation of thermal radiation.

Humidity is also one of the parameters affecting thermal comfort. Its effect becomes strong at high temperature and in the presence of a large concentration of particles. This is especially true in naturally ventilated buildings in the tropics where the temperature is hot and humidity is high [44-46]. The present study deals with low temperature $\left(21-22^{\circ} \mathrm{C}\right)$ with an inlet temperature of $-5^{\circ} \mathrm{C}$ representing winter condition when humidity is rather low. Therefore, the effect of humidity is assumed to be negligible in this study.

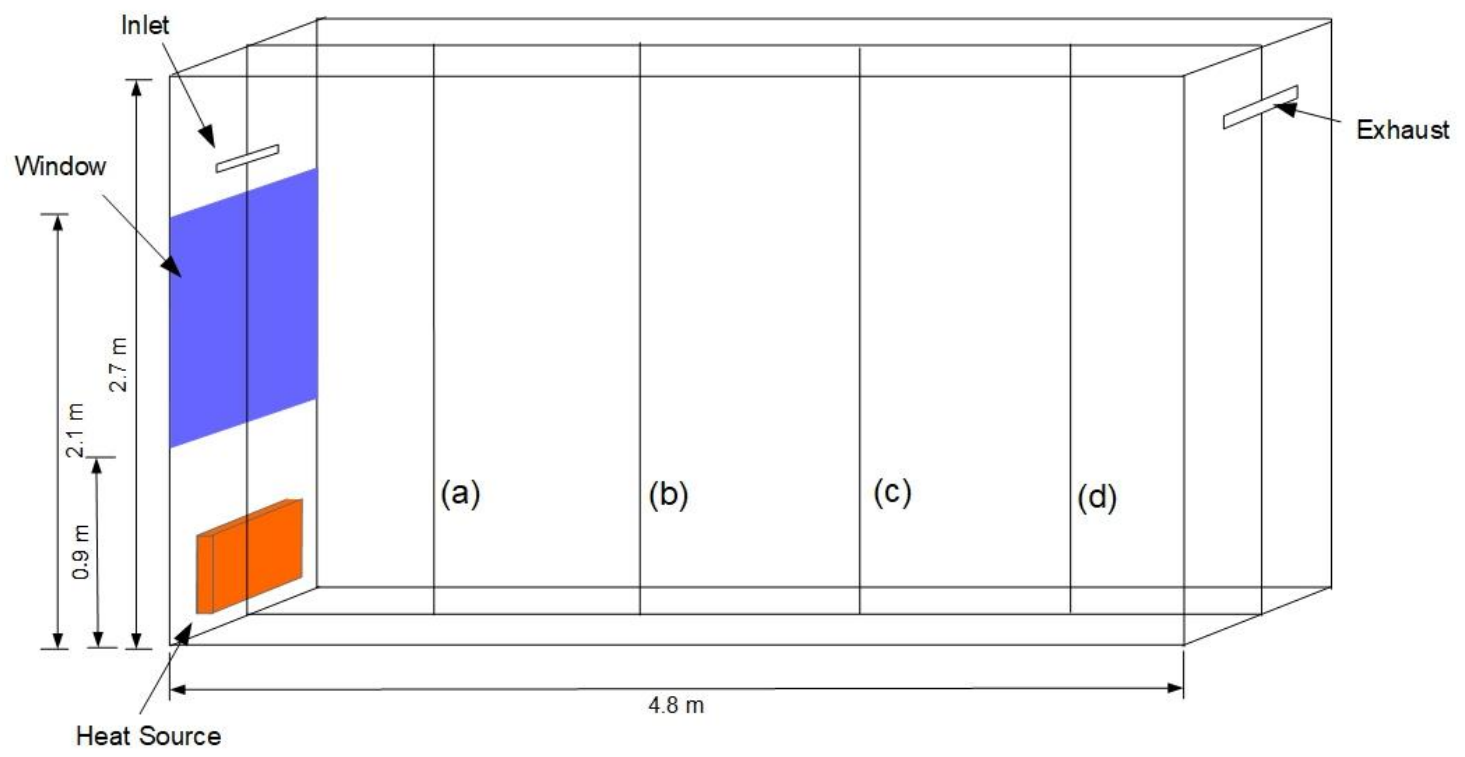

Figure 1: Diagram showing the room model along with the different components. (a), (b), (c) and (d) are the monitoring lines

\section{Numerical Model}

Numerical analysis of flow requires the solution of the governing equations of fluid dynamics and the energy equation along with the appropriate turbulence models. The conservative form of the governing equations are given below [33]:

$$
\frac{\partial \rho}{\partial t}+\nabla \cdot(\rho \vec{V})=0
$$




$$
\begin{aligned}
& \frac{\partial(\rho u)}{\partial t}+\nabla \cdot(\rho u \vec{V})=-\frac{\partial p}{\partial x}+\frac{\partial \tau_{x x}}{\partial x}+\frac{\partial \tau_{y x}}{\partial y}+\frac{\partial \tau_{z x}}{\partial z}+\rho f_{x} \\
& \frac{\partial(\rho v)}{\partial t}+\nabla \cdot(\rho v \vec{V})=-\frac{\partial p}{\partial y}+\frac{\partial \tau_{x y}}{\partial x}+\frac{\partial \tau_{y y}}{\partial y}+\frac{\partial \tau_{y z}}{\partial z}+\rho f_{y} \\
& \frac{\partial(\rho w)}{\partial t}+\nabla \cdot(\rho w \vec{V})=-\frac{\partial p}{\partial z}+\frac{\partial \tau_{x z}}{\partial x}+\frac{\partial \tau_{y z}}{\partial y}+\frac{\partial \tau_{z z}}{\partial z}+\rho f_{z}
\end{aligned}
$$

Turbulence in the flow was modelled with the Renormalization Group (RNG) $k-\varepsilon$ and $k-\omega$ Shear Stress Transport turbulence models. The turbulence models solve the Reynolds Averaged Navies-Stokes equation along with the equations of the production of turbulence kinetic energy $(k)$, its dissipation rate $(\varepsilon)$ and specific dissipation rate $(\omega)$.

The RNG $k-\varepsilon$ model is a two equation turbulence model derived from the Navier Stokes equation using the renormalization group theory. In this model, accuracy for rapidly strained flows is enhanced and swirling flows are also accounted for. An analytically derived formula for effective viscosity in RNG accounts for low Reynolds number effect. This model also provides an analytical formula for turbulent Prandtl number. The constitutive equations of the RNG $k-\varepsilon$ model are as follows [43]:

$$
\begin{gathered}
\frac{\partial}{\partial t}(\rho k)+\nabla(\rho k \vec{v})=\nabla\left(\alpha_{k} \mu_{e f f} \nabla k\right)+G_{k}+G_{b}-\rho \varepsilon-Y_{M}+S_{k} \\
\frac{\partial}{\partial t}(\rho \varepsilon)+\nabla(\rho \varepsilon \vec{v})=\nabla\left(\alpha_{k} \mu_{e f f} \nabla \varepsilon\right)+C_{1 \varepsilon} \frac{\varepsilon}{k}\left(G_{k}+G_{3 \varepsilon}+G_{b}\right)-C_{2 \varepsilon} \rho \frac{\varepsilon^{2}}{k}-R_{\varepsilon}+S_{\varepsilon}
\end{gathered}
$$

The $k$ - $\varepsilon$ SST model is an empirical based on the transport equations of $k$ and $\omega$, which is the ratio of $\varepsilon$ to $k$. It blends the standard $k$ - $\omega$ model in the near wall region and the high standard $k-\varepsilon$ model in the free stream region and also accounts for the transport of turbulent shear stress. Transport equations for $k$ and $\omega$ are respectively given as follows [29]:

$$
\begin{array}{r}
\frac{\partial}{\partial t}(\rho k)+\frac{\partial}{\partial x_{i}}\left(\rho k u_{i}\right)=\frac{\partial}{\partial x_{j}}\left(\Gamma_{k} \frac{\partial k}{\partial x_{j}}\right)+G_{k}-Y_{k}+S_{k} \\
\frac{\partial}{\partial t}(\rho \omega)+\frac{\partial}{\partial x_{i}}\left(\rho \omega u_{i}\right)=\frac{\partial}{\partial x_{j}}\left(\Gamma_{\omega} \frac{\partial \omega}{\partial x_{j}}\right)+G_{\omega}-Y_{\omega}+D_{\omega}+S_{\omega}
\end{array}
$$

In this study, the DO radiation model is used for simulating radiative heat transfer in the room. The Radiative Transport Equation (RTE) is solved for a finite number of solid angles with a vector direction $\mathbf{s}$ in the global Cartesian system $(x, y, z)$.

The radiative transport equation is given as [43]:

$$
\nabla(I(\vec{r}, \vec{s}) \vec{s})+\left(a+\sigma_{s}\right) I(\vec{r}, \vec{s})=a n^{2} \frac{\sigma T^{4}}{\pi}+\frac{\sigma_{s}}{4 \pi} \int_{0}^{4 \pi} I\left(\vec{r}, \vec{s}^{\prime}\right) \times \phi\left(\vec{r}, \vec{s}^{\prime}\right) d \Omega^{\prime}
$$

Dimensionless numbers relevant to the numerical simulations are given below:

Grashof number:

$$
G r=\frac{g \beta\left(T_{\text {radiator }}-T\right) L^{3}}{v^{2}}
$$

Rayleigh number:

$$
R a=\frac{g \beta\left(T_{\text {radiator }}-T\right) L^{3}}{v \alpha}
$$

Reynolds number: 


$$
R e=\frac{\rho V L}{\mu}
$$

The Reynolds number in this study is 2135.7. This has been calculated using the characteristic length of the inlet supply. Grashof's number is calculated using the height of the room as the characteristic length and the Rayleigh number is obtained by multiplying Grashof's number with the Prandtl number $(0.7)$ of air at the reference temperature. Fluids properties are taken at a reference temperature of $20^{\circ} \mathrm{C}$.

Table 1. Dimensionless numbers

\begin{tabular}{|l|l|}
\hline Reynolds Number (Re) & $\mathbf{2 1 3 5 . 7}$ \\
\hline Rayleigh Number (Ra) & $4.6 \times 10^{10}$ \\
\hline Grashoff's Number (Gr) & $6.4 \times 10^{10}$ \\
\hline $\mathbf{G r} / \mathbf{R e}^{2}$ & $1.4 \times 10^{4}$ \\
\hline
\end{tabular}

The ratio $\frac{\mathrm{Gr}}{\mathrm{Re}^{2}}$ gives the relative importance of natural and forced convection. If the ratio $\frac{\mathrm{Gr}}{\mathrm{Re}^{2}}>>1$, the flow is considered being dominated by natural convection. In natural convection flow is dominated by buoyancy. Simulation of buoyancy using the RANS equations requires assuming the fluid as a Boussinesq fluid or as an ideal gas. In this study, it is assumed that air is a Boussinesq fluid. An additional term known as the Boussinesq parameter, given below, is added as a source term in the momentum equation.

$$
\rho=\rho_{\text {ref }}\left(1-\beta\left(T-T_{\text {ref }}\right)\right)
$$

\section{THERMAL COMFORT}

In this section the parameters used for the analysis of thermal comfort is presented. The operative temperature and the comfort temperature are used in quantifying the temperature perceived by the occupant in the room. The formulae for calculating these parameters are given below [41]:

$$
\begin{aligned}
& T_{\text {Operative }}=\frac{T_{\text {radiation }}+T_{\text {air }}}{2} \\
& T_{\text {Comfort }}=\frac{T_{\text {Radiation }}+\left(T_{\text {air }} \times \sqrt{\left(10 \times u_{\text {air }}\right)}\right)}{1+\sqrt{\left(10 \times u_{\text {air }}\right)}}
\end{aligned}
$$

Radiation temperature is given as [29]:

$$
T_{\text {Radiation }}^{4}=\frac{1}{4 \sigma} \int_{0}^{4 \pi} I d \Omega
$$

The operative temperature is the mean of the air temperature and the mean radiant temperature. It accounts for the effect of radiation on the perceived temperature of an occupant. On the other, the comfort temperature takes into consideration the effects of air temperature, radiation temperature and air velocity on the temperature perceived by the occupant. The vertical temperature gradient is the difference between the temperature at the head level and the feet level. Discomfort may arise when this gradient becomes very large. The ISO 7730 [49], has set the limit for the maximum allowable temperature gradient as:

$$
T_{1.1}-T_{0.1}<3^{\circ} \mathrm{C}
$$

where $T_{1.1}$ is the temperature at $1.1 \mathrm{~m}$ above the floor and $T_{0.1}$ is the temperature at $0.1 \mathrm{~m}$ from the floor level. 


\section{RESULTS AND DISCUSSIONS}

Results were calculated at four vertical monitoring lines on the mid-plane along the streamwise direction. These vertical lines are assigned as ' $a$ ', 'b', 'c' and ' $d$ ', and are at a distance of $0.6 \mathrm{~m}, 1.8 \mathrm{~m}, 3.0 \mathrm{~m}$ and $4.2 \mathrm{~m}$ respectively from the left wall of the room (Figure 1).

Profiles of comfort temperature from this study are plotted in Figure 2. They show a good agreement with the numerical works of Myhren and Holmberg [37] and Horikiri et al. [39]. The figure shows that the temperature distribution is uniform and falls within a narrow range, but close to the heating element the temperature is less uniform [Figure 2(a)]. The comfort temperature profile in Figure 2(a) bends to the right at the lower regions; here the effect of radiation and natural convection are the strongest. Close to the heat source the rising thermal plume from the heat source driven by buoyancy counteracts the cold draft from the inlet, causing a non-uniform flow in this region. Further away, the temperature is more uniform as the effects of radiation and buoyancy diminish. The comfort temperature predicted by RNG and $k-\omega$ shows the same profiles at all the monitoring lines.

Heat maps of comfort temperature along the streamwise plane in the middle of the room are shown in Figures 4 and 5. Temperatures at an interval of $0.1 \mathrm{~m}$ on the plane are shown in the heat map, which serves as a convenient way of visualising the comfort temperature distribution in the room. A colour gradient captures the variation in comfort temperature across the plane. Looking at the heat map it is clear that the comfort temperature is nearly uniform across the room and is within a narrow range $\left(21-22^{\circ} \mathrm{C}\right)$. Location of the heat source just below the inlet is also important as it helps in heating the cold air and reducing its velocity before being distributed to other regions of the room. It is important to keep in mind that the room is not only heated by natural convection but also by radiation heat exchange between the room walls and the heating element; without considering radiation the numerical study could not make an accurate prediction of comfort. Occupants should be confined to the occupied zone $(0.6-4.2 \mathrm{~m})$ for experiencing the best comfort conditions; but if they are too close to the heat source excessive heating will endanger their comfort.

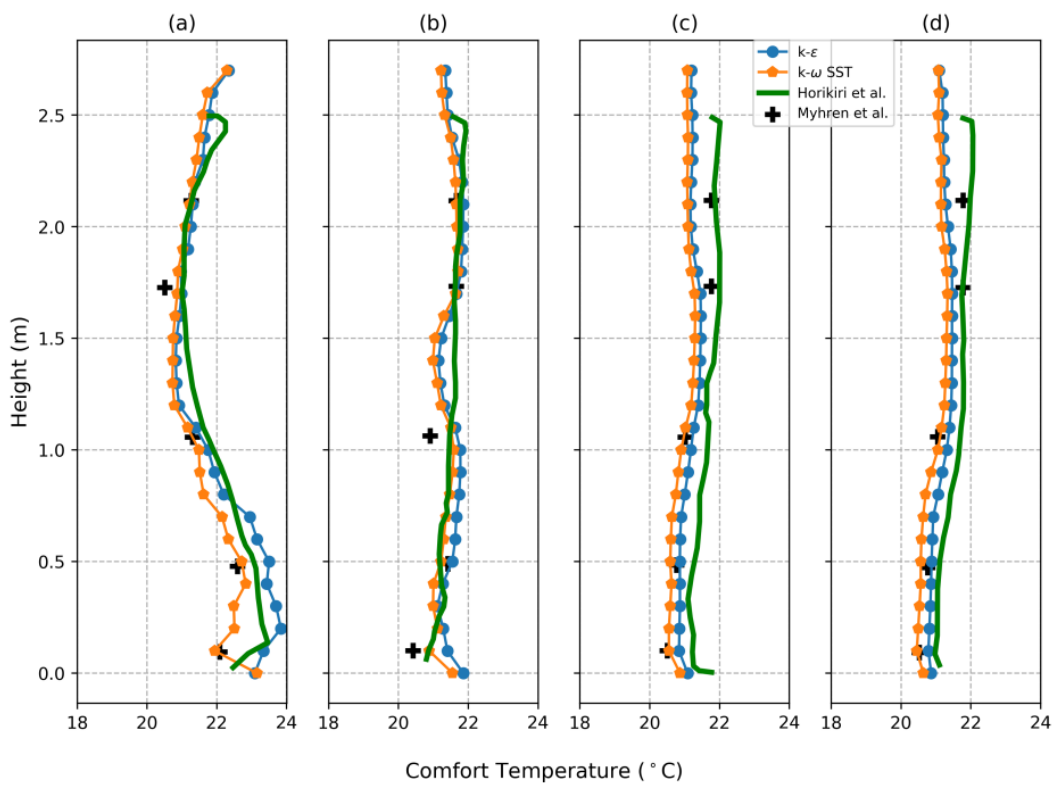

Figure 2. Comfort temperature profiles from the current study compared with Myhren and Holmberg [37]; and Horikiri et al., [40] 
(a)
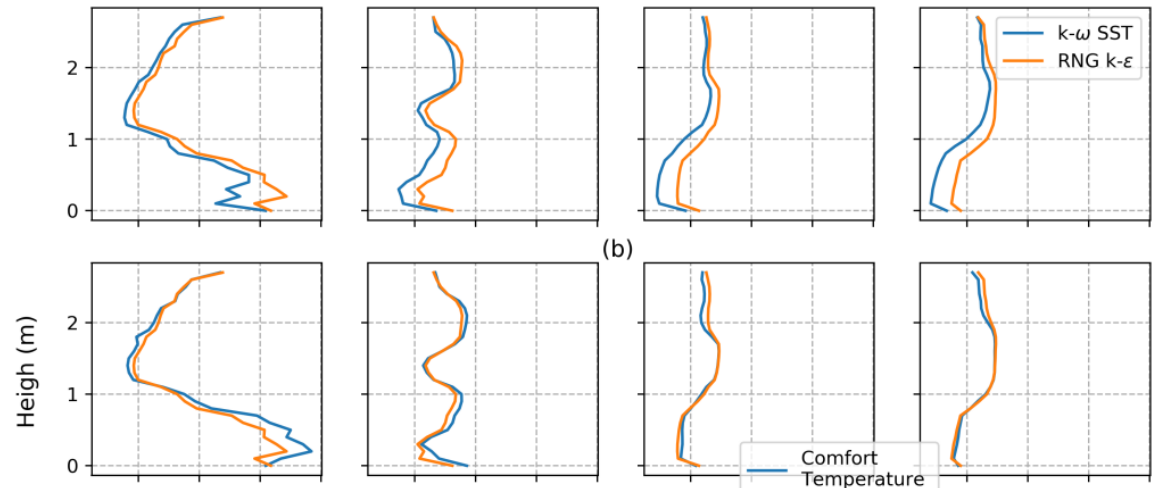

(b)
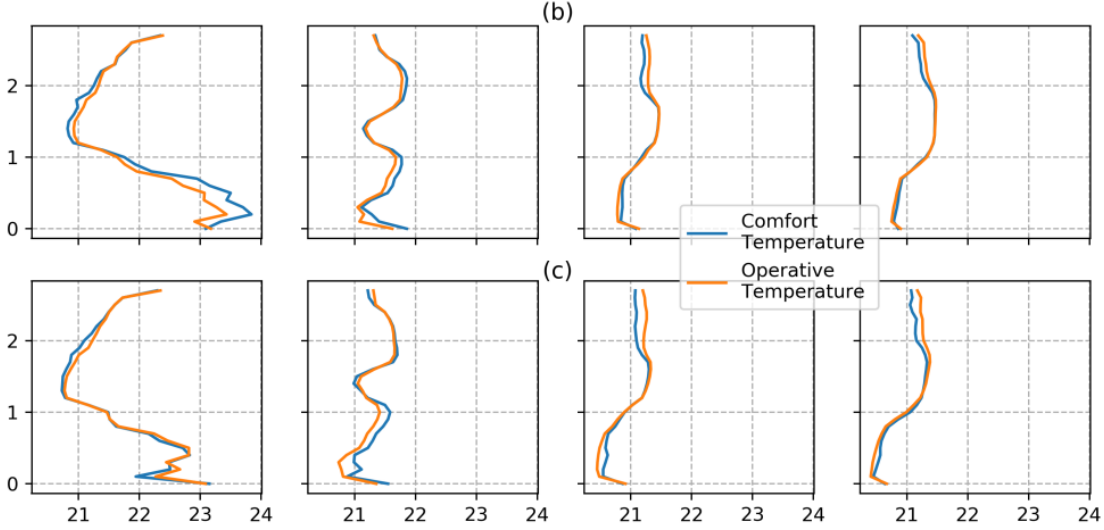

Operative Temperature $\left({ }^{\circ} \mathrm{C}\right)$

Figure 3. (a) Operative temperature profiles at the monitoring lines, (b) Comfort and operative temperature profiles from the RNG $k-\varepsilon$ model and (c) Comfort and operative temperature profiles from the $k$ - $\omega$ SST model.

The profiles of operative temperature are shown in Figure 3 and they are like that of comfort temperature. The equation of the comfort temperature and the operative temperature are given in equations 15 and 14 , respectively. It is interesting to note that the operative temperature do not include velocity in its calculation while comfort temperature does, yet they show the same profiles. It also worth pointing that the velocities predicted by the turbulence models are quite low and the similarity in the profiles of comfort and operative temperatures have to be understood within the context of low velocity.

Operative temperatures of RNG $k-\varepsilon$ and the $k$ - $\omega$ SST models are also compared and their profiles are found to be similar [Figure 3(a)]. The two turbulence models predict very similar comfort condition, proving their robustness and viability.

High temperature difference between the head and ankle level is known to cause discomfort. Along the four monitoring lines the differences are calculated as $0.7{ }^{\circ} \mathrm{C}, 1.1{ }^{\circ} \mathrm{C}, 0.8^{\circ} \mathrm{C}$ and $0.7^{\circ} \mathrm{C}$ respectively for the RNG $k-\varepsilon$ model. The temperature differences satisfy the criteria given in Equation 17 . We see that the calculated values are within acceptable limits. Similar results were reported in the CFD simulation of Myhren and Holmberg [37] and the experiments of Olesen et al. [2]. The low temperature gradient can be attributed to the presence of heat source just below the inlet. The cold draft from the inlet mixes with the rising warm air and prevents draught. The inlet air coming in from the inlet flows downward and contacts the heat source, see Figures 7 and 8 . Figures 9 and 10 show the rising thermal plume from the heat source interacting with the cold inlet air. It is clear that the cold air gets heated before getting distributed to other regions of the room. In the absence of the heat source, the cold air would hit the floor without any heating, which would result in a colder temperature of air at the ankle level, increasing the temperature gradient between the head and ankle level. The presents of the heat source prevent such undesired temperature gradient.

Air velocity calculated by the simulations are plotted in Figure 6 as histogram plots. These plots show the distribution of velocities in the room on spanwise planes at $0.6 \mathrm{~m}, 1.2 \mathrm{~m}, 3.0 \mathrm{~m}$ and $4.2 \mathrm{~m}$ from the left wall. Higher ranges of velocities are observed in the regions near the inlet with the highest velocity exceeding $0.3 \mathrm{~ms}^{-1}$. Predicted percentage of dissatisfied (PPD) index calculated by Myhren and Holmberg [37] did not show significant discomfort in this region $(\mathrm{PPD}<10 \%)$ and the comfort temperature for this region was highest (Figure 2). High velocities in this region could have been offset by the presence of the heat source resulting in favourable values of PPD and comfort temperature. Further away from the inlet velocities are much lower 

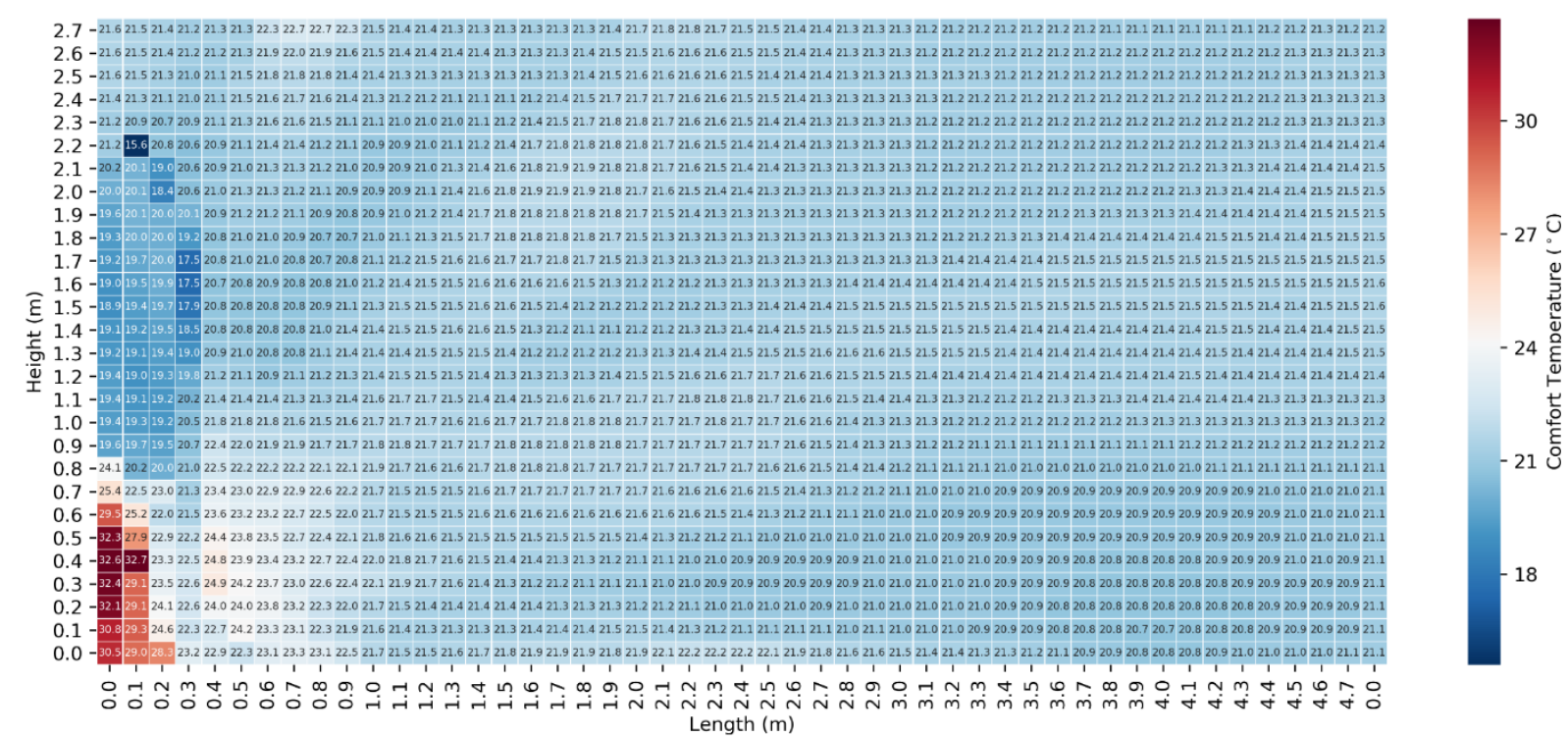

Figure 4. Heat Map of Comfort Temperature from RNG $k-\varepsilon$ model.

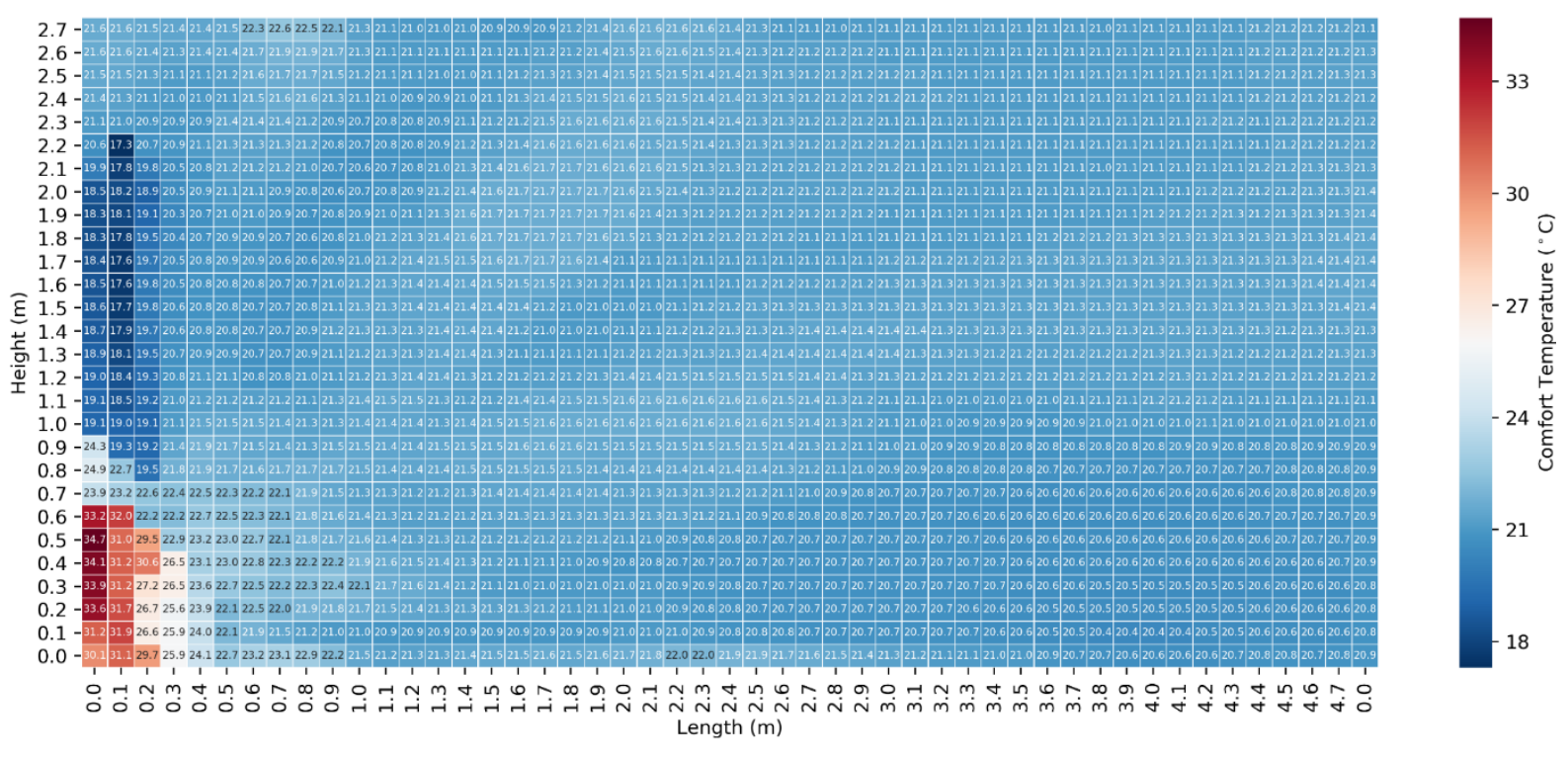

Figure 5. Heat Map of Comfort Temperature from $k-\omega$ SST model.

(Figure 6), well within the draught limit. Occupants are known to feel the movement of air at very low velocities [49,50]. A velocity of $0.15 \mathrm{~m} / \mathrm{s}$ is considered acceptable [48]. Any higher than this can cause draught, especially in cold climates

Vector and contour plots of velocity are shown in Figures 7 and 8, which show a small velocity. Except for the region near the heat source, all the other regions show a velocity of less than $0.1 \mathrm{~ms}^{-1}$ which is too small to cause draught related discomfort. Contour plots show the way the incoming cold air interacts with the heat source. The cold air $\left(-5^{\circ} \mathrm{C}\right)$ from the supply inlet comes into contact with the heat source, where it is heated before being distributed to other regions of the room. There is nearly uniform distribution of velocity across the room except for the region near the heat source. Unequal distribution of velocity would cause unwanted cooling in region of higher velocity, as this would increase the rate at which heat is removed from the exposed part of the body. Without the heat source air velocity would be higher, especially at the floor level as the cold inlet air would fall down on the floor and flow across the room unobstructed. Contour plots form the RNG $k-\varepsilon$ and $k-\omega$ models are similar; both of them predicting the same velocity distribution. 
(a)

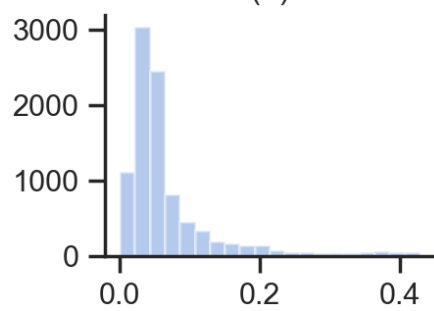

(a)

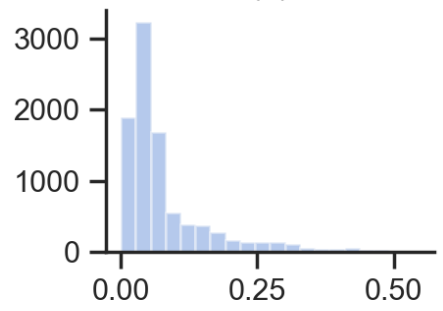

(b)

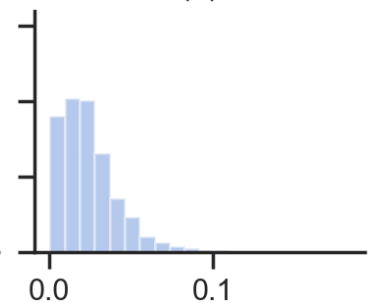

(b)

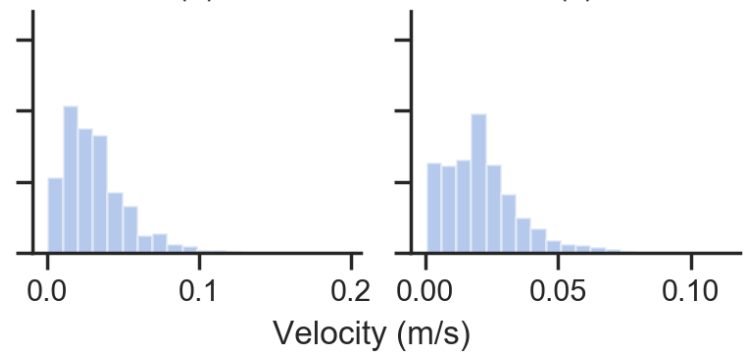

(c)

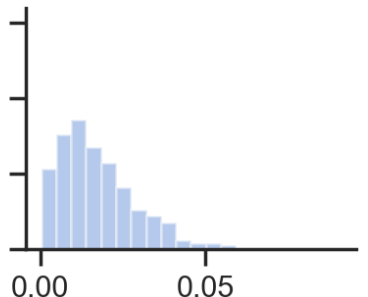

(c)

(d)

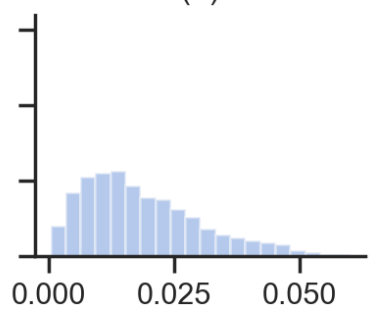

(d)

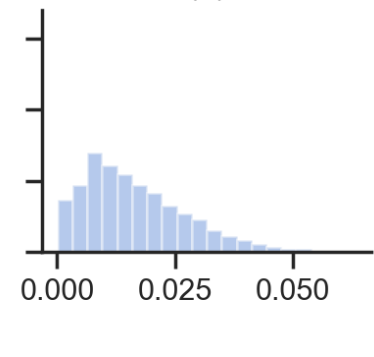

Figure 6. Histogram plots of velocity along spanwise planes at $0.6 \mathrm{~m}(\mathrm{a}), 1.2 \mathrm{~m}$ (b), $3.0 \mathrm{~m}$ (c) and $4.2 \mathrm{~m}$ (d) from the left wall. (Top: RNG $k-\varepsilon$ model, bottom: $k-\omega \mathrm{SST}$ )

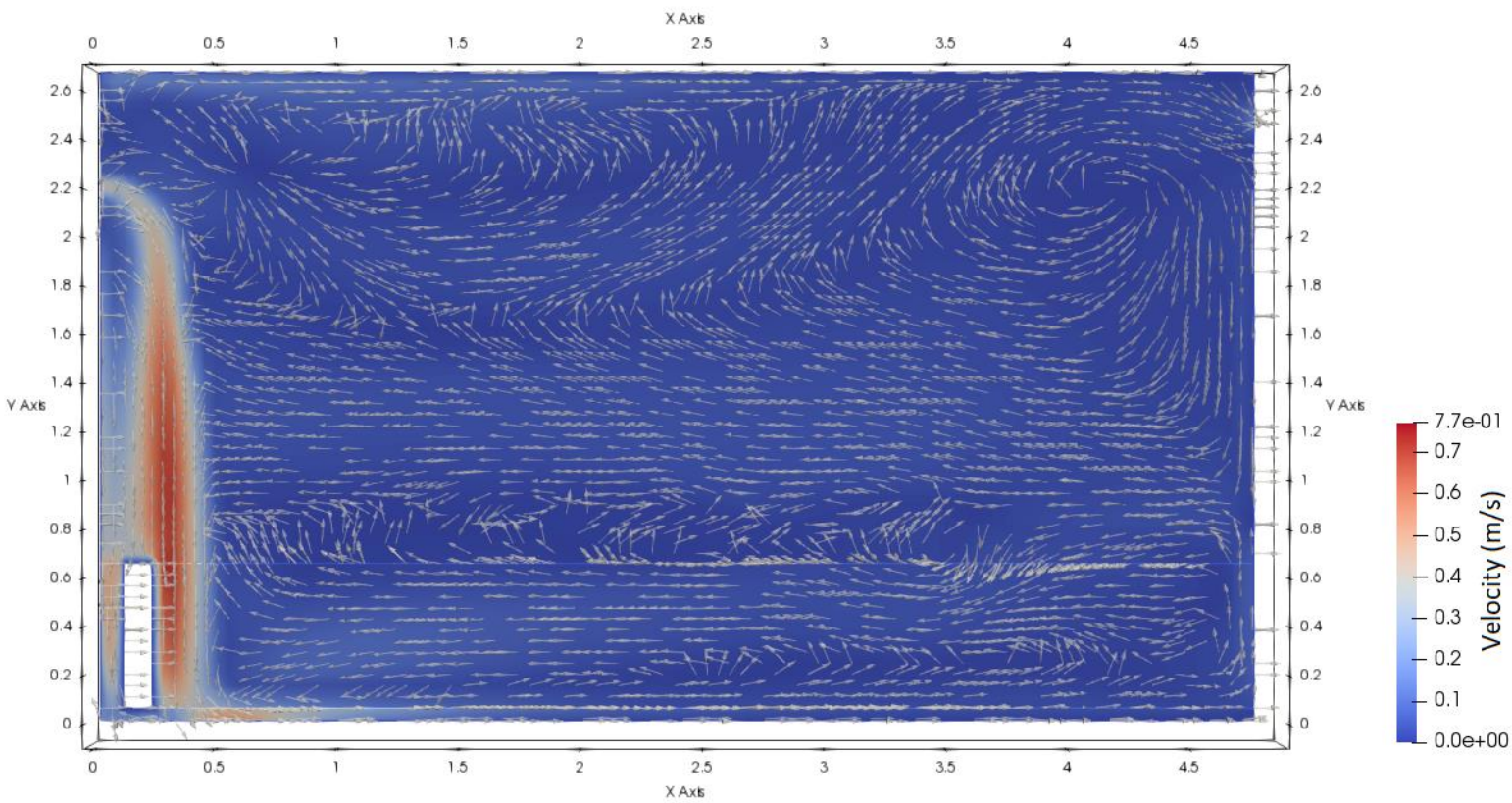

Figure 7. Vector and contour plot of velocity from the RNG $k-\varepsilon$ model.

The velocity vectors indicate the direction of air movement in the room and show a lot of recirculating region. Vector and contour plots of velocity, shown in Figures 9 and 10, demonstrates the influence of the heat source on the movement of air.

The histogram plots of turbulence intensity are shown in Figure 11. Its value is spread over a wider range (between 0 and 0.1 ) near the heat source because of the non-uniformity induced by buoyancy. Moving away from the heat source, its value decreases and its spread over a narrower range along with an increasing uniformity in air movement. Low turbulence flow are ideal for cold climates as it minimizes the risk of draught. Our study shows that the level of turbulence in the room is low enough to avoid the risk of draft and also that the predictions in its distribution made by the RNG $k-\varepsilon$ and the $k$ - $\omega$ SST models are alike. 


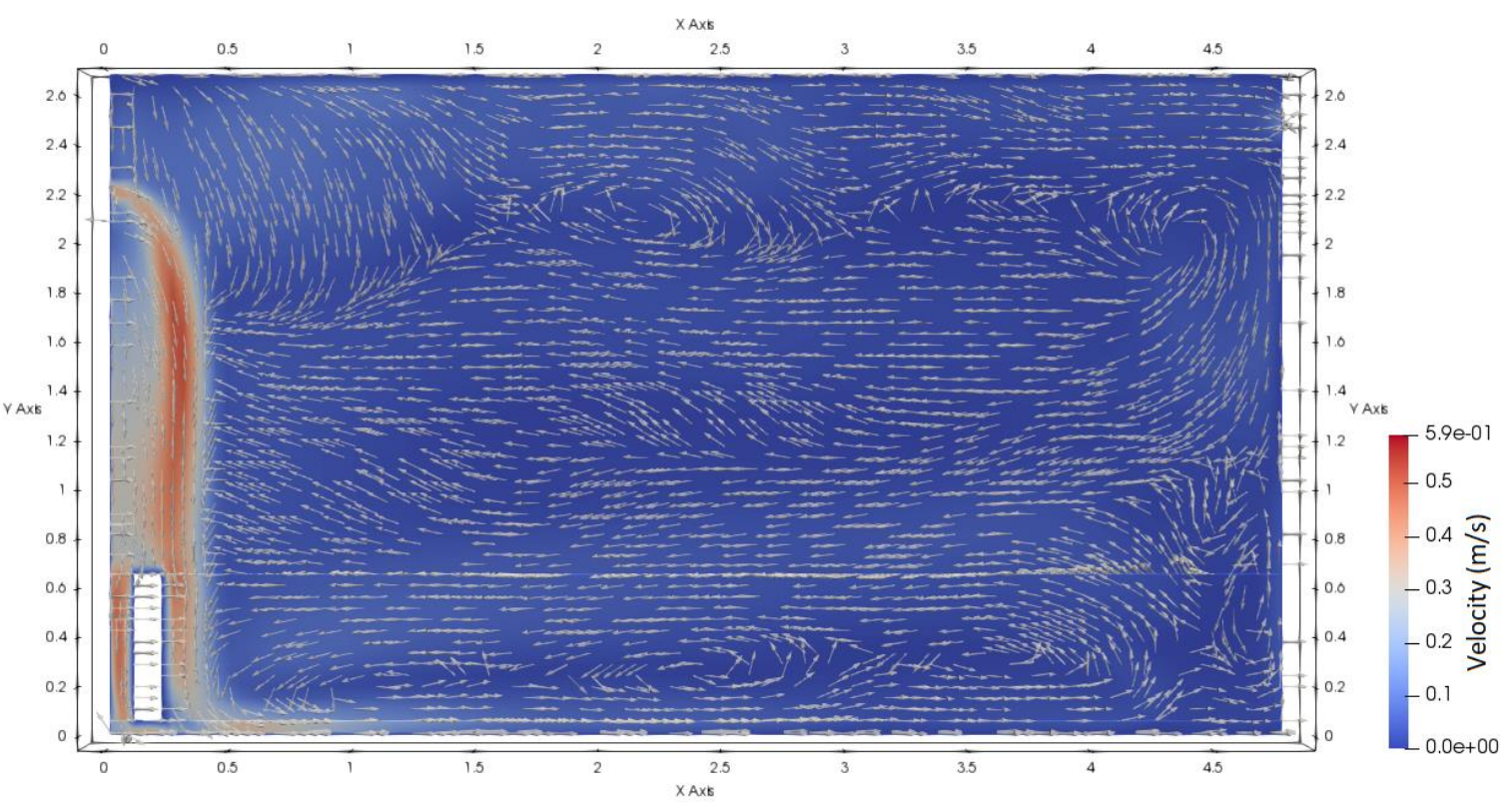

Figure 8. vector and contour plot of velocity from the $k-\omega$ SST model.

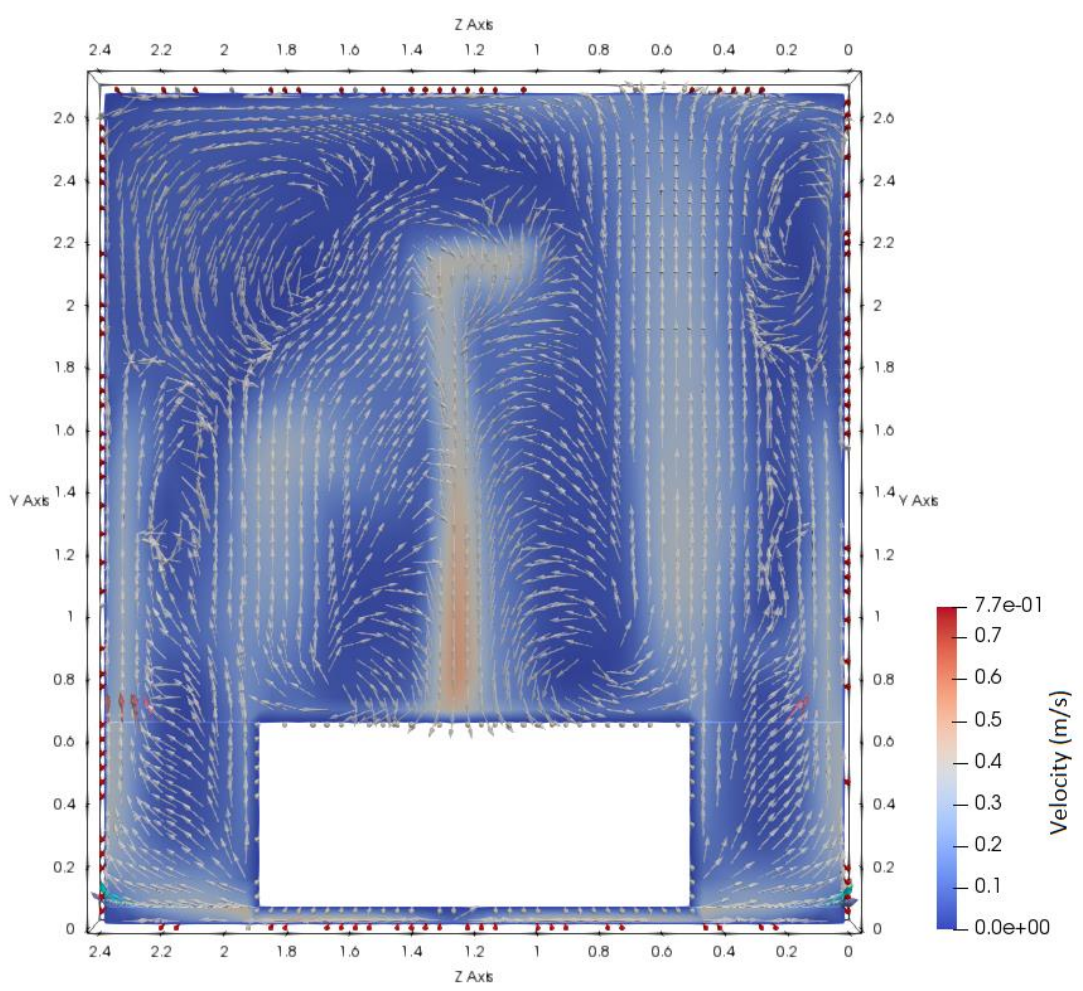

Figure 9. Vector and contour plot of velocity from the RNG $k-\varepsilon$ model at a spanwise plane across the heating element.

Contour plots of turbulence intensity near the source of heat are shown in Figure 12 and 13. These plots indicate a highly non-uniform distribution similar to the histogram plots of Figure 11. This numerical study predicts the condition in the room to be suitable for thermal comfort. Comfort temperature, operative temperature, velocity and turbulence intensity predicted are uniform at least in the occupied zone, which indicates a uniform flow condition in the room. Placement of the heat source just below the supply inlet is important as it influences the heat transfer (natural convection and radiation) and the distribution of velocity and turbulence in the room. Placing the heat source at other positions would cause different flow conditions and the comfort conditions would be changed accordingly. 


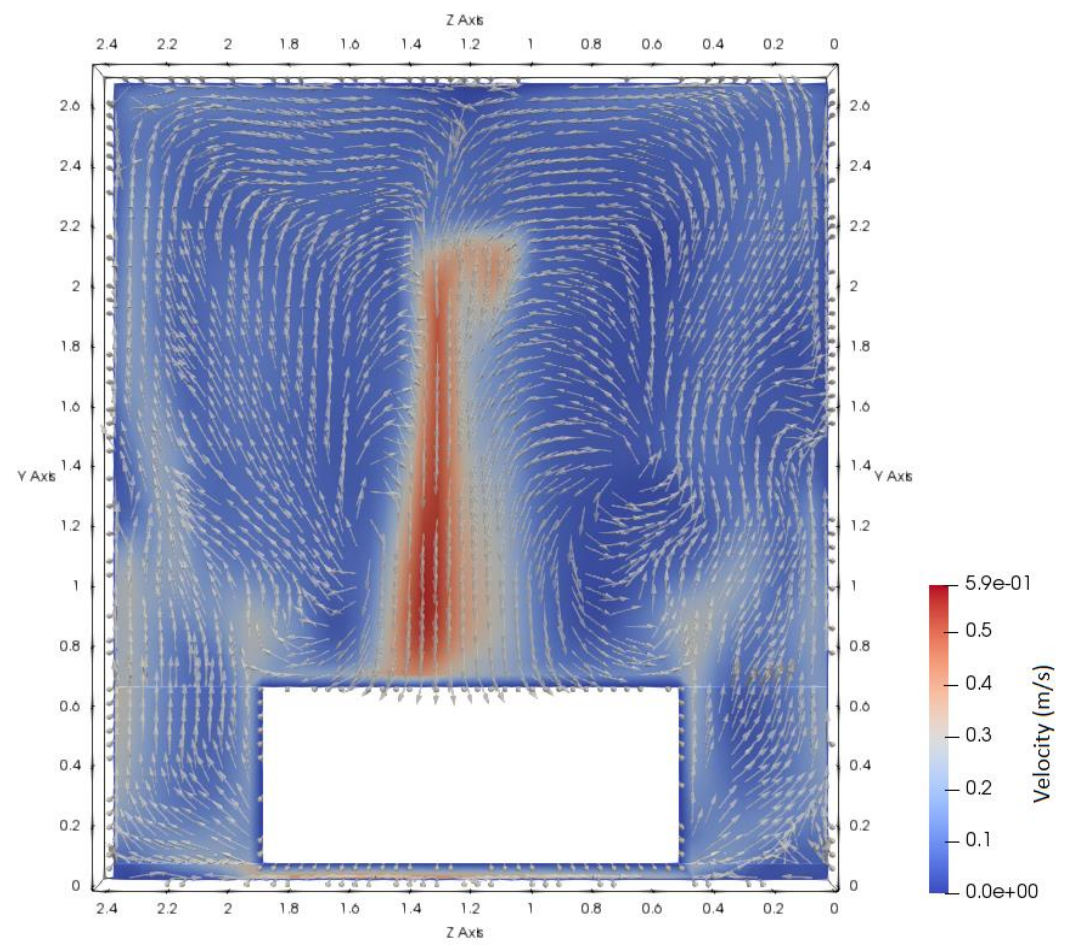

Figure 10. Vector and contour plot of velocity from the $k-\omega$ SST model at a spanwise plane across the heating element.

The RANS based turbulence models, i.e. RNG $k-\varepsilon$ and $k-\omega$ SST, utilized in this study predicts the same flow condition. In order for these turbulence models to simulated natural convection, air had to be approximated as a Boussinesq fluid, which increased the complexity of the simulation. Moreover, the presence of the heat source and the buoyant nature of flow makes it necessary to simulate radiation heat transfer as well, because flow velocity is too low to offset the effects of thermal radiation. The DO radiation models has been utilized for this purpose, which is computational more costly than other popular radiation model like the surface-to-surface (S2S), but has the ability to calculate the mean radiant temperature; this feature being not available for the latter.

It is worth mentioning that the RANS based turbulence models are quite robust in their predictions even though more advanced techniques for flow simulations such hybrid LES, LES and DNS are available, because of their ability to give a good generalization of flow at low cost.

(a)

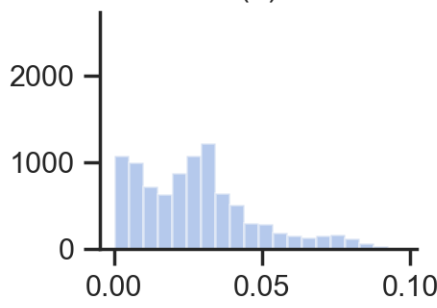

(a)

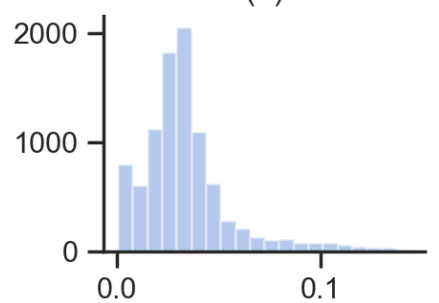

(b)

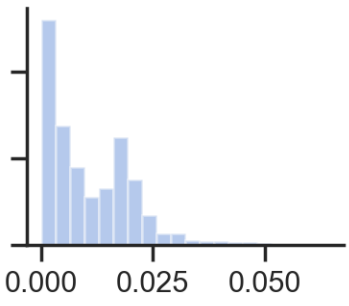

(b)

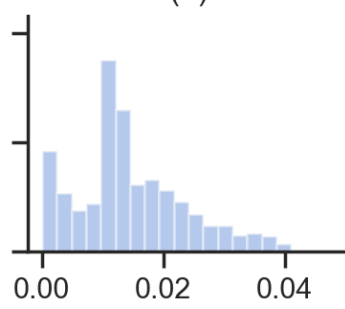

(c)

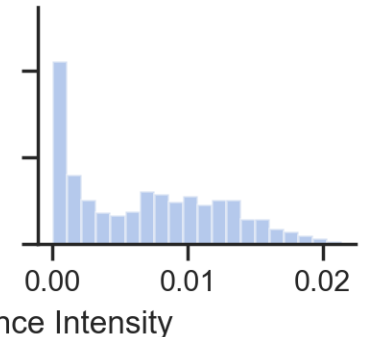

(c)

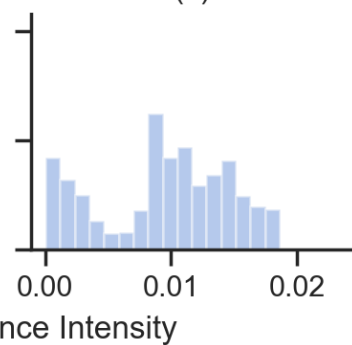

(d)

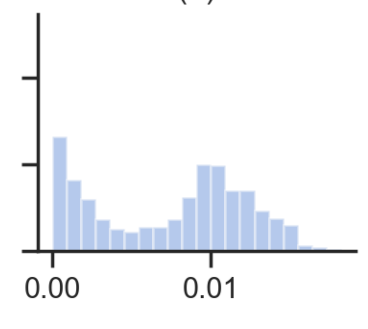

(d)

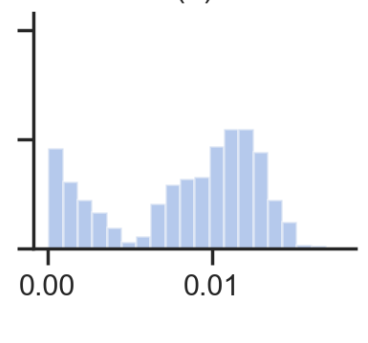

Figure 11. Histogram plots of turbulence intensity along spanwise planes at $0.6 \mathrm{~m}$ (a), $1.2 \mathrm{~m}$ (b), $3.0 \mathrm{~m}$ (c) and $4.2 \mathrm{~m}$ (d) from the left wall. (Top: RNG $k-\varepsilon$ model, bottom: $k-\omega \mathrm{SST}$ ) 
Journal of Thermal Engineering, Research Article, Vol. 7, No. 1, pp. 37-53, January, 2021

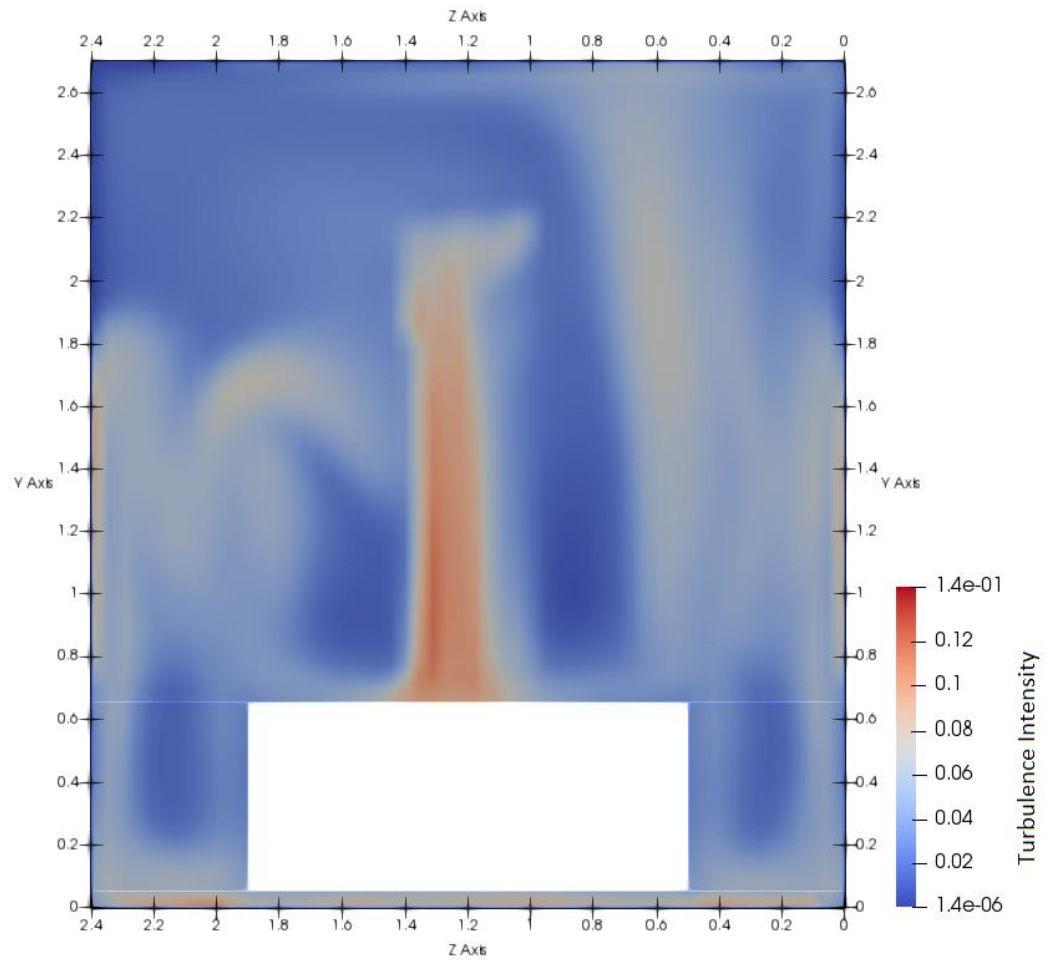

Figure 12: Contour plot of turbulence intensity from the $k-\omega$ SST model at a spanwise plane across the heating element.

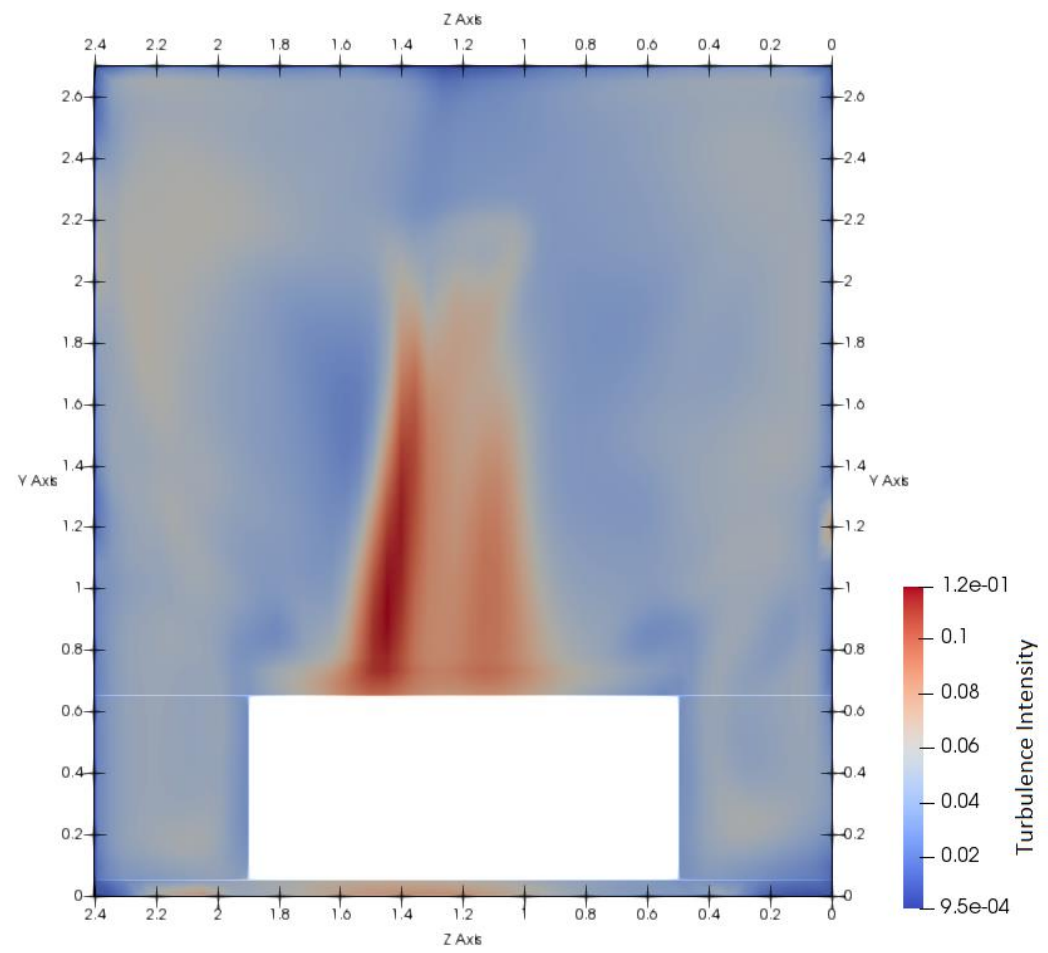

Figure 13. Contour plot of turbulence intensity from the $k-\omega$ SST model at a spanwise plane across the heating element. 


\section{CONCLUSION}

A heated room was numerically simulated to analyse its thermal comfort parameters. The buoyant air flow in the room exhibited a turbulent character because of a high Rayleigh number. Radiant heating by the heat source made significant contribution to the comfort temperature in the room. The effects of air and radiant temperatures were accounted for by the comfort indices.

The following conclusions can be drawn from this numerical study:

- The arrangement of the heating element just below the inlet supply gives a comfortable thermal environment. Cold air from the inlet mixes with the rising warm air heated by the heat source. Thus, the hazards of a cold draft are prevented.

- Predicted comfort and operative temperatures are between $20^{\circ} \mathrm{C}$ and $22{ }^{\circ} \mathrm{C}$, which gives a comfortable thermal feeling in the room for a winter climate. The two comfort indices were similar in their distribution in the room.

- The predicted velocities in the room were below $0.1 \mathrm{~ms}^{-1}$, so that the sensation of draught is at a minimum, while, at the same time feeling the movement of air.

- A low level of turbulence was predicted by the numerical simulations. A low value of turbulence intensity would reduce the risk of draught maintaining a comfortable environment in the room.

- The temperature difference between the head and ankle level is $0.7{ }^{\circ} \mathrm{C}, 1.1{ }^{\circ} \mathrm{C}, 0.8^{\circ} \mathrm{C}$ and $0.7^{\circ} \mathrm{C}$ at the four monitoring lines which are within the limit of $3{ }^{\circ} \mathrm{C}$ set by established international standards for minimum discomfort.

- The turbulence model used in this study gave similar results and were validated with other works. The numerical analysis predicts a thermal environment that meets established international standards. Even in the presence of more accurate simulation techniques such as Large Eddy Simulation (LES) and Direct Numerical Simulation (DNS), in situations where computational resources and time are lacking, RANS models provide a robust and viable alternative.

- In this final section, some limitations of this work are discussed.

- The room simulated in this work has a simple geometry with a single heat source and is not an accurate representation of a real room. Furniture, occupants and electronic equipment should be added to reproduce the complex flows observed in a real room.

- Only two turbulence models are evaluated in this work. The choice of turbulence models can either improve or diminish to quality of the numerical results and also decide the stability of the simulations. Evaluation of different turbulence models can help in deciding the best model for reproducing the complex environment in indoor spaces.

- In this study, the inlet condition (inlet velocity and temperature) is kept constant. However, a change in the inlet condition can produce different temperature and velocity profiles and affect the thermal comfort indices.

- The transport of contaminants is not considered in this study. Buoyant flows can have a strong influence on the transport of contaminants and proper design of a ventilation system requires an effective removal of contaminants as well as heat. Simulation of contaminant transport is time-consuming but it can shed important light on the effectiveness of the ventilation system.

- The walls, ceiling, and floor are assigned an adiabatic boundary condition, which is an idealization. Heat transmittance through the walls, windows, and ceiling results in a non-adiabatic boundary condition.

\section{NOMENCLATURE}

$\begin{array}{ll}a & \text { absorption coefficient }\left(\mathrm{m}^{-1}\right) \\ \mathrm{N}\left(a+\sigma_{s}\right) s & \text { optical thickness of the medium } \\ D_{\omega} & \text { cross diffusion term } \\ G_{k} & \text { generation of turbulence kinetic energy due to mean velocity gradient } \\ G_{b} & \text { generation of turbulent kinetic energy due to buoyancy } \\ G_{\omega} & \text { generation of } \omega \\ \mathrm{g} & \text { acceleration due to gravity }\left(\mathrm{ms}^{-2}\right) \\ I & \text { surface irradiation } \\ k & \text { turbulence kinetic energy }\left(\mathrm{Jkg}^{-1}\right)\end{array}$




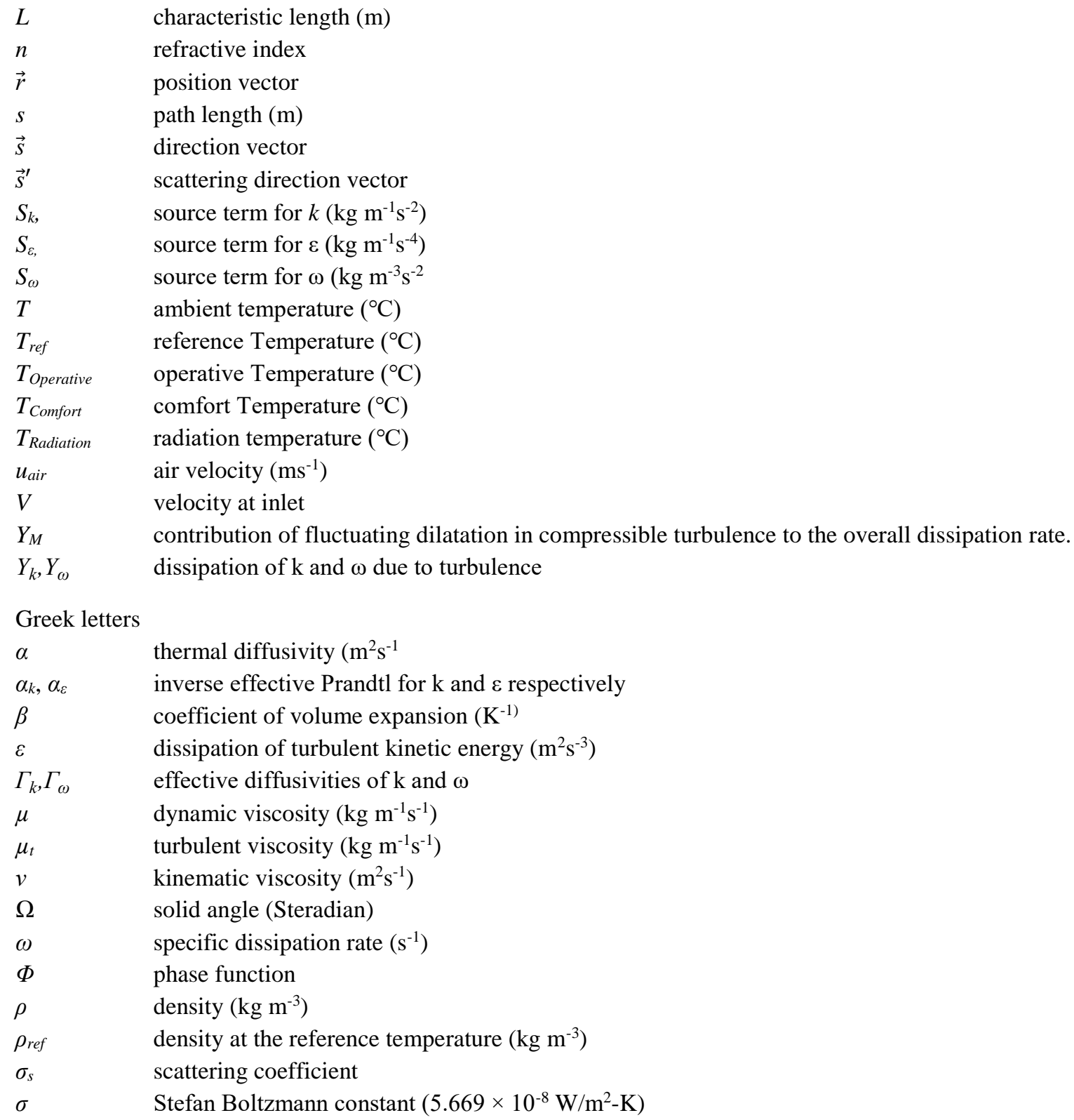

\section{REFERENCES}

[1] Fanger PO. Assessment of thermal comfort practice. Occup Environ Med 1973;30:313-24. https://doi.org/10.1136/oem.30.4.313.

[2] Olesen BW, Mortensen E, Thorshauge J, Berg-Munch B. Thermal Comfort in a Room Heated by Different Methods - Technical paper no. 2256. Los Angeles Meet ASHRAE Trans 86 1980:34-48.

[3] Turner SC, Paliaga G, Lynch BM, Arens EA, Aynsley RM, Brager GS, et al. Standard 55-2010 Thermal environmental conditions for human occupancy, Atlanta, GA 2010;2010:30.

[4] Sarafraz MM, Hormozi F. Forced convective and nucleate flow boiling heat transfer to alumina nanofluids. Period Polytech Chem Eng 2014. https://doi.org/10.3311/PPch.2206.

[5] Sarafraz MM, Hormozi F, Silakhori M, Peyghambarzadeh SM. On the fouling formation of functionalized and non-functionalized carbon nanotube nano-fluids under pool boiling condition. Appl Therm Eng 2016. https://doi.org/10.1016/j.applthermaleng.2015.11.071.

[6] Nakhjavani M, Nikkhah V, Sarafraz MM, Shoja S, Sarafraz M. Green synthesis of silver nanoparticles using green tea leaves: Experimental study on the morphological, rheological and antibacterial behaviour. Heat Mass Transf Und Stoffuebertragung 2017. https://doi.org/10.1007/s00231-017-2065-9. 
[7] Sarafraz MM, Nikkhah V, Madani SA, Jafarian M, Hormozi F. Low-frequency vibration for fouling mitigation and intensification of thermal performance of a plate heat exchanger working with $\mathrm{CuO} /$ water nanofluid. Appl Therm Eng 2017. https://doi.org/10.1016/j.applthermaleng.2017.04.083.

[8] Sarafraz MM, Nikkhah V, Madani SA, Jafarian M, Hormozi F. Low-frequency vibration for fouling mitigation and intensification of thermal performance of a plate heat exchanger working with $\mathrm{CuO} /$ water nanofluid. Appl Therm Eng 2017. https://doi.org/10.1016/j.applthermaleng.2017.04.083.

[9] Safaei MR, Rahmanian B, Goodarzi M. Numerical study of laminar mixed convection heat transfer of power-law non-Newtonian fluids in square enclosures by finite volume method. Int J Phys Sci 2011;6:7456-70. https://doi.org/https://doi.org/10.5897/IJPS11.1092.

[10] Safaei M, Goodarzi M, Mohammadi M. Numerical modeling of turbulence mixed convection heat transfer in air filled enclosures by finite volume method. Int J Multiphys 2011. https://doi.org/10.1260/1750-9548.5.4.307.

[11] Goodarzi M, Safaei MR, Karimipour A, Hooman K, Dahari M, Kazi SN, et al. Comparison of the finite volume and lattice boltzmann methods for solving natural convection heat transfer problems inside cavities and enclosures. Abstr Appl Anal 2014. https://doi.org/10.1155/2014/762184.

[12] Goodarzi M, Safaei MR, Oztop HF, Karimipour A, Sadeghinezhad E, Dahari M, et al. Numerical study of entropy generation due to coupled laminar and turbulent mixed convection and thermal radiation in an enclosure filled with a semitransparent medium. Sci World J 2014. https://doi.org/10.1155/2014/761745.

[13] Nikkhah V. Application of Spherical Copper Oxide (II) Water Nano-fluid as a Potential Coolant in a Boiling Annular Heat Exchanger. Chem Biochem Eng Q 2015. https://doi.org/10.15255/CABEQ.2014.2069.

[14] Goodarzi M, D’Orazio A, Keshavarzi A, Mousavi S, Karimipour A. Develop the nano scale method of lattice Boltzmann to predict the fluid flow and heat transfer of air in the inclined lid driven cavity with a large heat source inside, Two case studies: Pure natural convection \& mixed convection. Phys A Stat Mech Its Appl 2018. https://doi.org/10.1016/j.physa.2018.06.013.

[15] Goodarzi. M, Safaei. M.R, Vafai.K, Ahmadi. G, Dahari. M, Kazi. S.N JN. Investigation of nanofluid mixed convection in a shallow cavity using a two-phase mixture model n.d.

[16] Mou B, He BJ, Zhao DX, Chau KW. Numerical simulation of the effects of building dimensional variation on wind pressure distribution. Eng Appl Comput Fluid Mech 2017. https://doi.org/10.1080/19942060.2017.1281845.

[17] Akbarian E, Najafi B, Jafari M, Ardabili SF, Shamshirband S, Chau K. Experimental and computational fluid dynamics-based numerical simulation of using natural gas in a dual-fueled diesel engine. Eng Appl Comput Fluid Mech 2018;12:517-34. https://doi.org/https://doi.org/10.1080/19942060.2018.1472670.

[18] Ramezanizadeh M, Nazari MA, Ahmadi MH, Chau K. Experimental and numerical analysis of a nanofluidic thermosyphon heat exchanger. Eng Appl Comput Fluid Mech 2019;13:40-7. https://doi.org/https://doi.org/10.1080/19942060.2018.1518272.

[19] Wu CL, Chau KW. Mathematical model of water quality rehabilitation with rainwater utilisation: a case study at Haigang. Int J Environ Pollut 2006;28. https://doi.org/https://doi.org/10.1504/IJEP.2006.011227.

[20] Ardabili SF, Najafi B, Shamshirband S, Bidgoli BM, Deo RC, Chau KW. Computational intelligence approach for modeling hydrogen production: A review. Eng Appl Comput Fluid Mech 2018;12:438-58. https://doi.org/10.1080/19942060.2018.1452296.

[21] Chau KW, Jiang YW. Three-dimensional pollutant transport model for the Pearl River Estuary. Water Res 2002;36:2029-39. https://doi.org/10.1016/S0043-1354(01)00400-6.

[22] Senveli A, Dizman T, Celen A, Bilge D, Dalkilic AS, Wongwises S. CFD analysis of smoke and temperature control system of an indoor parking lot with jet fans. J Therm Eng 2015;1. https://doi.org/10.18186/jte.02276.

[23] Bhowmick S. ASSESSING THE IMPACT OF PASSIVE COOLING ON THERMAL COMFORT IN LIG HOUSE USING CFD. J Therm Eng 2019. https://doi.org/10.18186/thermal.623212.

[24] Açıkgöz Ö. DETERMINATION OF CONVECTIVE, RADIATIVE, AND TOTAL HEAT TRANSFER CHARACTERISTICS OVER A RADIANT HEATED CEILING: A COMPUTATIONAL APPROACH. J Therm Eng 2019. https://doi.org/10.18186/thermal.623191. 
[25] Buckmaster DJ, Abramson AR. Characterization of the effects of insulating wall paint on space conditioning in a room. J Therm Eng 2015;1. https://doi.org/10.18186/jte.03430.

[26] Eshack A, Samuel DGL, Nagendra SMS, Maiya MP. Monitoring and simulation of mechanically ventilated underground car parks. J Therm Eng 2015;1. https://doi.org/10.18186/jte.88079.

[27] Ganesh GA, Sinha SL, Verma TN. Numerical simulation for optimization of the indoor environment of an occupied office building using double-panel and ventilation radiator. J Build Eng 2020;29. https://doi.org/10.1016/j.jobe.2019.101139.

[28] Ganesh GA, Sinha SL, Verma TN. Effect of Inlet Airflow Direction on the Indoor Environment of a Naturally Ventilated Room using CFD. Int J Eng Adv Technol 2020;9:580-91. https://doi.org/10.35940/ijeat.c5112.029320.

[29] Verma TN, Sinha SL. Numerical Simulation of Contaminant Control in Multi-Patient Intensive Care Unit of Hospital Using Computational Fluid Dynamics. J Med Imaging Heal Informatics 2015;5:1088-92. https://doi.org/https://doi.org/10.1166/jmihi.2015.1500.

[30] Verma TN, Sinha SL. Contaminant Control in Intensive Care Unit of Hospital. Appl Mech Mater 2014;592-594:2486-90. https://doi.org/https://doi.org/10.4028/www.scientific.net/AMM.592-594.2486.

[31] Verma TN, Sahu AK, Sinha SL. Study of Particle Dispersion on One Bed Hospital using Computational Fluid Dynamics. Mater Today Proc 2017;4:10074-9. https://doi.org/10.1016/j.matpr.2017.06.323.

[32] Verma TN, Sinha SL. Contaminant control in intensive care unit of hospital. Appl Mech Mater 2014;592594:2486-90. https://doi.org/10.4028/www.scientific.net/AMM.592-594.2486.

[33] Nath Verma A T, Lata Sinha A S. Trajectory of Contaminated Particle in Intensive Care Unit of Hospitals Using Numerical Modeling. Int J Des Manuf Technol 2015;9:43-7. https://doi.org/10.18000/ijodam.70150.

[34] Verma TN, Sahu AK, Sinha SL. Numerical Simulation of Air Pollution Control in Hospital. Air Pollut. Control. Energy, Environ. Sustain., Springer Nature Singapore; 2018, p. 185-206. https://doi.org/10.1007/978-981-10-7185-0_11.

[35] Verma TN, Sahu AK, Sinha SL. Numerical simulation of air flow to ventilate intensive care unit of hospital. Comput. Appl. Educ. Res. Sci. Technol., vol. 1, International Research Publication House; 2018, p. 131-8.

[36] Teodosiu C, Kuznik F, Teodosiu R. CFD modeling of buoyancy driven cavities with internal heat source Application to heated rooms. Energy Build 2014;68:403-11. https://doi.org/10.1016/j.enbuild.2013.09.041.

[37] Myhren JA, Holmberg S. Flow patterns and thermal comfort in a room with panel, floor and wall heating. Energy Build 2008;40:524-36. https://doi.org/10.1016/j.enbuild.2007.04.011.

[38] Myhren JA, Holmberg S. Design considerations with ventilation-radiators: Comparisons to traditional two-panel radiators. Energy Build 2009;41:92-100. https://doi.org/10.1016/j.enbuild.2008.07.014.

[39] Horikiri K, Yao Y, Yao J. Modelling conjugate flow and heat transfer in a ventilated room for indoor thermal comfort assessment. Build Environ 2014;77:135-47. https://doi.org/10.1016/j.buildenv.2014.03.027.

[40] Horikiri K, Yao Y, Yao J. Numerical optimisation of thermal comfort improvement for indoor environment with occupants and furniture. Energy Build 2015;88:303-15. https://doi.org/10.1016/j.enbuild.2014.12.015.

[41] Myhren J, Holmberg S. Comfort temperatures and operative temperatures in an office with different heating methods 2006:0-5.

[42] Patankar S V., Spalding DB. A calculation procedure for heat, mass and momentum transfer in threedimensional parabolic flows. Int J Heat Mass Transf 1972;15:1787-806. https://doi.org/10.1016/00179310(72)90054-3.

[43] ANSYS, Inc. (2016) ANSYS Fluent User's Guide, Release 17.

[44] de Dear RJ, Leow KG, Ameen A. Thermal comfort in the humid tropics. Part I. Climate chamber experiments on temperature preferences in Singapore. ASHRAE Trans 1991;97:874-9.

[45] de Dear RJ, Leow KG, Ameen A. Thermal comfort in the humid tropics. Part II. Climate chamber experiments on thermal acceptability in Singapore. ASHRAE Trans 1991:880-6. 
Journal of Thermal Engineering, Research Article, Vol. 7, No. 1, pp. 37-53, January, 2021

[46] de Dear RJ, Leow KG, Foo SC. Thermal comfort in the humid tropics: Field experiments in air conditioned and naturally ventilated buildings in Singapore. Int J Biometeorol 1991;34:259-65. https://doi.org/10.1007/BF01041840.

[47] Wendt JF, Anderson JD, Degroote J, Degrez G, Dick E, Grundmann R, et al. Computational fluid dynamics: An introduction. 3rd ed. Springer-Verlag Berlin Heidelberg; 2009. https://doi.org/10.1007/978-3-540-85056-4.

[48] ISO-7730. International Organization for Standardization: Moderate Thermal Environments determination of the PMV and PPD indices and specification of the conditions for thermal comfort. International Organization for Standardization, 1994.

[49] Fanger PO, Christensen NK. Perception of draught in ventilated spaces. Ergonomics 1986;29:215-35. https://doi.org/10.1080/00140138608968261.

[50] Fanger PO, Melikov AK, Hanzawa H, Ring J. Air turbulence and sensation of draught. Energy Build 1988;12:21-39. https://doi.org/10.1016/0378-7788(88)90053-9. 